\title{
Navigating role forces and the aesthetic|authentic caring dialectic: a novice urban science teacher's developmental trajectory
}

\author{
Maria S. Rivera Maulucci
}

Received: 23 May 2009/Accepted: 26 July 2009/Published online: 21 August 2009

(C) The Author(s) 2009. This article is published with open access at Springerlink.com

\begin{abstract}
Examining role forces and resources available to new teachers is crucial to understanding how teachers use and expand cultural, social, and symbolic resources and how they engage teaching for social justice and caring in urban science education. This critical narrative inquiry explores three levels of story. First, the narratives explore my role as a district science staff developer and my efforts to leverage district resources to improve students' opportunities to learn science. Second, the narratives explore the ways in which a novice science teacher, Tina, navigated role forces and the aestheticlauthentic caring dialectic in a high poverty, urban school. A third level of narrative draws on sociological theories of human interaction to explore role forces and how they shaped Tina's developmental trajectory. I describe how Tina expanded cultural, social, and symbolic resources to enact her teaching role.
\end{abstract}

Keywords Authentic caring - Aesthetic caring - Role forces - Critical narrative inquiry · New teacher mentoring

\section{Setting the scene...}

It is 1:30 and the Fifth grade class scheduled for a microscope lab is already half an hour late. The children finally arrive, and from their expressions I realize that they did not cooperate with their teacher, Renee, while coming down to the Lab. I ask Renee to pair the students, while I show them where to sit. Renee is a slim, softspoken, African-American woman. This is her first year teaching. She quietly begins pairing the students, mostly boy-girl. Students begin to complain. Some try to sit with different partners, while others push their chairs as far from each other as possible. Amid the chairs scraping the floor, are the discordant notes of students' unkind words to each other, some more vociferous than others, and I am unsure how I will accomplish anything in the next hour. I try to soothe them and wonder how I

M. S. Rivera Maulucci $(\bowtie)$

Barnard College, Columbia University, New York, NY, USA

e-mail: mriveram@barnard.edu 
can move them from their current locations of anger and frustration and engage them in science...

As I prepare to address the class, I know that I must do or say something to bridge the gap between my students' pain and anger and the science we are supposed to engage in. I tell them, 'I can see that you are having a bad day'. Many students nod their heads or murmur in agreement. I continue, 'In an ideal world, we would all be sitting next to someone we like and get along with. But in the real world, sometimes we have to sit with someone...' A boy loudly finishes for me, 'We don't like!' I ask him, 'Would you want your partner to say that about you?' He says, 'No'. I continue, 'Anyway, I believe that we can change our luck ... that if we're having a bad day ... we can just decide to have a good day. What do you think?' (Field notes, September 2001)

\section{A social justice framework}

In my work as a district science staff developer, I tried to provide a model for urban science teaching. Like Renee, many of the teachers I worked with had fewer than 5 years of teaching experience and many also lacked the science content knowledge and confidence to teach science effectively. Many struggled with issues of classroom management and establishing learning communities. During model lessons in my lab, I hoped to provide an alternative to the authoritarian, teacher-directed, textbook-driven pedagogies that often defined science teaching in many of the schools in my urban district. As a Latina in science, with 16 years teaching in middle schools, a teacher educator, and a multicultural, feminist researcher, I sought to redress inequities within my daily lived experiences (Knight 2000). Thus, I approached this study with a social justice and caring lens that focused on ways to make science more accessible to teachers and students in the particular context of a low-performing urban school. At the same time, I hoped to document the ways in which our struggles might inform the broader struggle for social justice in urban science education.

I define social justice in science education as an ongoing struggle to re-envision and enact a more caring, equitable, and agentic schooling, in general, and science education, in particular. I specifically use the term, 're-envision', to recognize that the teachers and students I work with already have visions for caring, science, and science education. At the same time, the term re-envision incorporates an integral part of my role as a staff developer: to move teachers and students towards actively developing classroom communities that foster respect, caring, inquiry-based learning, problemsolving, and student achievement in science. This is not to imply that some or all of these aspects are not already present. Thus, I also recognize that re-envisioning caring, science, and science education is an ongoing process that never ends. I expect to grow, and change, and re-envision caring, science, and science education alongside those I work with.

\section{Reflecting on Renee's class}

When students enter my lab for the first time, I let them know that learning can be different...that we can change our luck. I will be different...they can be different...their teachers can be different... and science can be different. I rarely do so in explicit ways 
and change takes more than a few words. Renee's class came a long way since that first time they entered my lab and much of the change had little to do with what happened that day or anything I did. Yet, can reflection on such moments point to possibilities of re-envisioning science education? As a staff developer, I struggled with just how transformative my pedagogy was for students, teachers, parents, schools, and communities. For example, to what extent might three to four visits to my lab influence science pedagogy back in the classroom? In what ways did students gain a different understanding of themselves as learners and as partners in learning? In what ways did teachers begin to reflect on their role and change some of their teaching practices? Did students and teachers begin to re-envision what it means to care about each other and about science?

I also questioned the ways in which science-school science or everyday science- was transformed for students and teachers. In other words, how were their perceptions, attitudes, and beliefs about science challenged by their experiences in the lab? How did students and teachers resolve any challenges? How would I know if, or when, any transformations occurred? Yet, I recognize that social justice in urban science education is an ideal that I aspire to, and continue to approximate. Thus, the focus of this study is to describe what happened at the interplay between theories and practices of caring and social justice in the context of my work in the lab. In particular, this study focuses on the journey of one new teacher and some of the ongoing reflection and action, or praxis that lies at the core of transforming pedagogy (Freire 1970).

\section{Re-envisioning caring in science education}

\section{Back to Renee's class...}

It is almost time for the magic of science to begin...that time when I let the students explore and discover something new ... that time when science almost never fails to excite, motivate, or engage students. The task: to explore all the movable parts of the microscope with a partner and discuss what the parts could do. Most students had never used a microscope before and despite their seeming inability to work with each other moments ago, they quickly settle into the task. The room hums with excitement. Some students need reminders to let their partners have a turn, but most effectively negotiate their shared space and shared responsibilities.

I circulate for a few minutes to several different groups, asking questions about students' ideas, without confirming or denying them. Then, I notice one boy, Juan, who seems disengaged from the task. I approach, thinking that his partner, Luis, is not giving him a turn. I remind Luis to give Juan a turn and he says, 'I tried to give him a chance, but he didn't want to do it'. As I look at Juan, I can see tears forming, and I remember how strongly the two had resisted working together. I know that whatever history there was between the two, the allure of science, or learning something new, or having the opportunity to manipulate a microscope is not enough for Juan ... not yet. I gently, but firmly, tell Juan that he has two choices ... he can continue to sit there, angry and unhappy, or he can try to work with Luis and learn something new. I tell him that Luis is willing to share the microscope and work with him. Luis nods his head encouragingly. Juan looks at Luis, then at me. I encourage the boys to work together and then move on to the next group of students. A few 
minutes later, I glance over to see both boys discovering how the microscope works, and I wonder what they saw in each other's eyes. (Field notes, September 2001)

\section{Authentic|aesthetic caring}

Valenzuela (1999) contends that educators must become sensitive to the 'politics of caring' as a first step in developing a 'more relevant and authentic pedagogy' (p. 255). In her study of Mexican youth, Valenzuela found a key difference in the ways that students and teachers perceived caring. Specifically, teachers expected students to care about school, including ideas and practices that foster achievement, while students expected teachers to care about them, stressing reciprocity and respect. According to Valenzuela, students at Seguin experienced a more 'aesthetic', or superficial, version of care, in which the school paid more attention to historical or institutional norms than to the types of caring or nurturing relationships students experienced. This basic disconnect led to a mutual sense of alienation for both teachers and students. When the students entered my lab, angry and frustrated, I could have chosen to ignore their social locations. I could have dismissed the struggles they brought with them to class as irrelevant or overlooked the gender dynamics that developed. I could have insisted on focusing on science. We had limited time and there was so much I wanted them to learn. I could have ignored Juan ... if he did not care about school that was his choice. However, I would have privileged scientific knowledge and skills over the students' more basic need to feel that I cared for them. The exchange between the class and me, showed the students that I recognized, understood, and cared about how they were feeling. While I did not put aside the entire educative process, I acknowledged their pain. The exchange between Juan, Luis, and me, showed Juan that I cared about him and how he was feeling, not just whether he was working. Juan was also able to see that Luis was willing to work with him. Ultimately, caring paved the way to learning.

Valenzuela (1999) defines authentic caring as a 'reformulation' in which 'school functionaries are to embark on a search for connection where trusting relationships constitute the cornerstone for all learning' (p. 263). Her concept of authentic caring draws on Noddings' (1995a, b) themes of care. According to Noddings (1995a):

All children must learn to care for other human beings, and all must find an ultimate concern in some center of care: care for self, for intimate others, for associates and acquaintances, for distant others, for animals, for plants and the physical environment, for objects and instruments, for ideas. (p. 366)

Furthermore, we should demand more from education than 'adequate academic achievement' and 'we will not achieve even that meager success unless our children believe that they themselves are cared for and learn to care for others' (Noddings 1995b, pp. 675-676). Caring is more than 'a warm fuzzy feeling that makes people kind and likable. Caring implies a continuous search for competence' (p. 676). Thus, teachers must continuously look for ways to improve their teaching.

A 'caring, competent, and qualified teacher for every child is the most important ingredient in education reform and ... the most frequently overlooked' (National Commission on Teaching \& America's Future (NCTAF) 1996, p. 3). Yet, how do parents, students, and teachers define caring? Each vignette in the report speaks to a commitment to students as individuals, to understanding how students learn, and creating active learning 
environments that enable students to enjoy discovering, rather than covering the curriculum. For example, Joanne Leavitt, a parent, describes good teachers:

Good teachers are those who can transmit a passion for learning. They believe all children can learn, some may take a bit longer, but will not stop until they have tried everything they can and then some. They understand that learning is a lifelong experience and let their children see they are still learning ... Good teachers care about their students as people, not just grades in a book. (p. 24)

The vignettes show that caring in teaching closely connects with a continuous search for competence and a belief that every student can learn. According to teacher Frank Lazant, 'teachers should constantly evaluate and adjust their methods in the classroom to better meet the needs of students and society' (NCTAF 1996, p. 7). Another teacher, W. Dean Eastman explains: 'A lot of times we don't expect enough of students. That to me is a lack of respect ... If they don't get it, just sit down and be with them. It seems to work' (p. 27).

Defining authentic and aesthetic caring

The parent and teacher vignettes reveal an inherent tension between authentic and aesthetic caring in schools. I define authentic caring as student-centered caring, focused on the individual and collective needs, interests, capacities, and cultures of youth and teachers. Authentic caring manifests itself through the nature of social interactions, curricular structures that are responsive to students' needs, interests, and cultures, curricular content that explicitly attends to caring, and school cultures that foster respect, solidarity, and learning. On the other hand, aesthetic caring focuses on institutional priorities, such as programming, rules, policies, procedures, and accountability mechanisms. Aesthetic caring may be crucial to the smooth operation and effectiveness of schools; however, when schools privilege aesthetic caring over authentic caring, subtractive schooling ensues (Valenzuela 1999). For example, schooling becomes subtractive when it divests immigrant youth of their linguistic, cultural, and social resources, subjecting many to failure. Schooling becomes subtractive when it focuses attention on how students represent themselves, using their dress or speech as indicators of their concern for school and achievement. Similarly, school-wide policies, such as tracking and segregation, may have harmful effects for students in low tracks (Gilbert and Yerrick 2001). In addition, heightened accountability and high-stakes testing regimes may erode professionalism, quality of science instruction, and relationships between teachers and students (Settlage and Meadows 2002). Finally, schooling becomes subtractive when a culture of low expectations and apathy indicates that teachers, staff, and administrators have succumbed to a sense of hopelessness.

In a dialectical relationship, each parameter implies the existence of the other (Roth et al. 2005). Thus, the existence of aesthetic caring beliefs and practices presupposes the existence of authentic caring beliefs and practices. While authentic caring and aesthetic caring need not be diametrically opposed, we must interrogate school policies and structures when they place deep constraints on the possible relationships students and teachers might create and when they serve to reproduce social inequality. How might I use my position as a district science staff developer to begin to address some of the entrenched inequalities I observed in the high-poverty urban schools in my district? How could I enact an ethic of caring and justice in ways that modeled for teachers how to navigate the tensions of the aestheticlauthentic caring dialectic in their schools? 
A place I call home...

Nestled on the second floor of a beautiful, 10-year-old school building is the Science Lab. The Lab was developed as part of a district science initiative to support science teaching and learning in 52 schools. As part of regional restructuring and mayoral control of city schools, we merged with an adjoining district to serve over a hundred schools, many designated high-need. I am at home in this Lab, in this school, and in this community. The abundance of science books and materials appeals to my inner science nerd. I love experimenting with new science activities and each draw or box I open yields new and exciting materials to explore. When classes come to the Lab, brown and black skins and the multilingual voices and cadences of 'the hood' surround me. Did I say, I feel at home here? I must stress this point, because when I walk the halls of the school, I do not notice deficits in speech, language, dress, or behavior. When I go upstairs to confer with the administrators, they welcome me, and I serve on the school's planning committee. When I walk the streets of the community, I do not notice graffiti, squalor, crumbled sidewalks, or rusted elevated trains. Instead, I see beauty in the tropical paradises that spring up in the windows of the apartment houses. I do not fear gangs or crime although both are known to be part of life in this community. I know the local store owners by name, and the father of a student I taught years ago at another school calls me if I forget to move my car so I do not get ticket for parking during street cleaning. I grew up in a neighborhood not too far from here, and a 10-min car ride brings me to my mother's house in the Bronx, a place I still call home... (April, 2009)

Establishing the context...

This study took place in a large, K-8 public school in New York City. As Director of a district science professional development lab (Lab) housed in the school, I worked with teachers in the school as they planned and implemented their science curriculum. I spent most of my time in a science laboratory on the second floor teaching model science lessons for classes and teachers in the school and from other schools in the district. While descriptors, such as failing and high-poverty might be ascribed to the school, students, or community, these labels by no means account for individual or collective possibilities for educational achievement, empowerment, or civic engagement. Thus, I provide the following school data to illustrate the challenges the school faced, rather than to list a series of deficiencies.

School report card data show that $65 \%$ of students at the school were Latino/a, $33 \%$ were Black, and $2 \%$ were White, Asian, and others. About $4 \%$ of the students were recent immigrants, mainly from the Dominican Republic. The attendance rate for 2003 was $90 \%$ and $90 \%$ of the students were eligible for free or reduced school lunch. Almost all of the teachers, were White, fully licensed, and permanently assigned (not long-term substitutes) to the school. However, only $43 \%$ had taught more than 2 years at the school, a measure of teacher retention, and only $30 \%$ had more than 5 years of teaching experience, one measure of teacher quality. The school opened in 1993. By 1996, the school was declared a 'SURR' school (School under Registration Review) by New York State for low reading and mathematics scores. The school was redesigned in 1999, and despite overall trends of slight improvement each year, the intermediate grade levels were restructured in spring 2004. Table 1 summarizes school achievement data for fourth and eighth grade students in the first year of the study. The data provide a snapshot of student performance in English Language Arts, Mathematics, and Science during the 2002-2003 school year. As stated 
Table 1 Percent of students meeting the standard

Performance levels 3 and 4

a Similar schools are other schools in New York City with similar ethnic data and poverty indices

b Percent of students scoring above the state designated level, raw score of 30 out of 45 on multiple choice portion of test

\begin{tabular}{clll}
\hline & This school & Similar schools $^{\mathrm{a}}$ & City schools \\
\hline Grade 4 & & & \\
ELA & 24 & 40 & 53 \\
Math & 42 & 56 & 67 \\
Science & 23 & 37 & 48 \\
Grade 8 & & & \\
ELA & 13 & 23 & 34 \\
Math & 16 & 30 & 40 \\
Science & 16 & 32 & 46 \\
\hline
\end{tabular}

earlier, my goal is to highlight the challenges the school faced to improve student achievement.

Introducing Tina and the study

In fall 2002, the school hired five new Fifth grade teachers. In this school, the Fifth grade was considered part of the middle school, although teachers taught all subjects to one class of students. One of the new teachers, Tina, is the focus of this study. Tina was a White female who had grown up in a predominantly White, middle class, suburb of the city. She graduated from college with a degree in Psychology, and worked as a teaching assistant for a year in a preschool before applying to the New York City Teaching Fellows Program (NYCTF). The NYCTF program, established in spring 2000, is an alternative route certification program that seeks to attract professionals from other careers into teaching to address teacher shortages in high-need schools (Costigan 2004). The Fellows complete a rigorous application process, including intensive interviews, teaching a demonstration lesson, and review of their academic and employment backgrounds. After a five-week summer training, Tina was placed in the school. She simultaneously enrolled in a 36-credit, local graduate education program, paid for by the NYCTF. She committed to teach at least 2 years in the City, the duration of her Masters Degree program. Currently, the program requires seven-week summer training and partially subsidizes the Masters Degree program (NYC Department of Education, 2008).

To tell Tina's story, I draw on data from a larger study of the three Fifth grade teachers, including field notes from teacher meetings, classroom observations, and semistructured interviews. As a participant observer, I conducted about 10 observations each year during Tina's class visits to the Lab and science lessons in her classroom. Classroom observations focused on student and teacher interactions, adjustments Tina made to her teaching in response to students' needs and interests, linkages between planning and implementing science lessons, and evidence of student learning. I conducted a life history interview with Tina in spring 2003, detailing experiences in and out of school that helped formulate her beliefs about science, her role as a science learner, and her vision or philosophy of teaching science. During a second interview in fall 2003, I asked Tina to describe and give examples of the ways the teachers' caring community helped transform her science teaching. In a follow-up interview conducted in spring 2004, I explored the unique challenges and opportunities afforded by the urban context of Tina's science teaching. Data analysis was ongoing and proceeded in a recursive and inductive fashion 
so that themes identified early on were explored in subsequent data gathering sessions (Strauss and Corbin 1998).

Seeing the world through a narrative lens...

I am drawn to stories. A good story draws me in, takes me outside myself, and leaves me fundamentally changed ... I am the same but different somehow, just by virtue of having listened to, or told, a story. There are many stories that make up our lives, but the most important ones show us where we need to change and how to go about transforming ourselves and our world. These are the 'critical' stories, the ones that excavate institutional and structural inequalities related to race, gender, and class so that by uncovering them, they might be transformed (Calabrese Barton 2001). Teacher stories help us make sense of classroom practices (Clandinin and Connelly 2000) and situate understanding and thinking about teaching and learning in a particular time, personal and social context, and physical space (Clandinin et al. 2007). Above all, teacher stories convey the emotions, hopes, desires, values, and goals of the storyteller, and the participants in the story. I call what I do critical narrative inquiry, a blending of my researcher/teacher/reformer roles that takes me outside the stance of passive observer or unbiased researcher. I make my social justice stance explicit by sharing readings, engaging teachers in discussions, and modeling practices I believe will transform science teaching and learning and enhance students' opportunity to learn. I focus on student engagement, critical thinking, and analysis, development of scientific literacy and English literacy skills, sustaining hope, and fostering personal and classroom transformation. In a school that serves predominantly poor, Black, and Latino/a students, groups traditionally underrepresented in the sciences, I leverage resources available in the Lab to ameliorate institutional and structural inequalities. I address the low priority of science in the school, the lack of resources to teach science, and the absence of student-centered approaches to teaching science. Immersed in this field of inquiry and enmeshed in its politics, I seek to describe some of the nuances of this particular context and its participants (Pole and Morrison 2003). The narratives capture the multiple roles I play, the events that occur, my feelings and impressions, and how they help me re-envision teaching for social justice in urban science education (Geelan 1997).

\section{Navigating aesthetic|authentic caring role forces}

In the following sections, I develop a series of narratives. The narratives detail Tina's struggles as a new teacher and how she pulled together and took on the role of an effective teacher. They show how effective teaching helped her feel confident teaching science in inquiry-based ways, and how Tina began to assert her science teaching authority in an owl pellet unit by the end of her second year of teaching. Threaded through each of the narratives are the ways in which Tina negotiated competing demands of aestheticlauthentic caring in her efforts to make and receive verification for her role as a science teacher. In constructing the narratives, I have chosen to tell her story in my voice. As the storyteller, I can point explicitly to the ways her story had, and continues to have, transformative value for me, and the work that I do as a teacher educator. In keeping with the prior sections, I use indented and regular text to distinguish between narratives from the field and narratives from my researcher perspective. 
A new teacher...

Tina wanted to be a teacher since she was in the Fifth grade. She had the coolest firstyear teacher, who did numerous hands-on projects and activities. Tina wanted to be just like her and even began wearing similar clothes. Despite her early desire to become a teacher, Tina chose an alternative teacher certification route, the New York City Teaching Fellows program. She admitted that as an undergraduate, she did not want to put in the extra work or effort to complete a teacher education program. Instead, she found out about the Teaching Fellows program during her junior year, and decided to apply to the program after she graduated.

What was she thinking? How could her knowledge of teaching, grounded in her suburban schooling experiences possibly prepare her to teach in a high-need, hardto-staff, public school in New York City? Could the easy success of her Fifth grade teacher be leading her on? Did she think she could learn what she needed on the job? Was her decision fair to the Black and Latino/a students in the school? Fastforward from Renee's story 1 year, and I have Tina, another novice teacher, coming to my lab late, with tears in her eyes, and telling me, 'These four children are not participating today!' I gently told her, 'We cannot deny students an opportunity to learn science. If you want them to wait on the side while I give the introduction, that's okay, but they need to participate.' Tina was struggling as a new teacher and needed support. She admitted to me that she had no idea what she was doing. She believed the administrators left her high and dry and only came down on her when she was doing something wrong. All she wanted was for someone to tell her how to teach, how to do it 'right.' She just wanted to know, because then, she could do it.

In taking on the role of teacher, Tina drew on her available stocks of knowledge about schools and the roles of teachers and students. Stocks of knowledge include preassembled roles, such as traditional images of the teacher lecturing, while students sit quietly and listen, and generalized roles, such as what it means to be assertive, compliant, and respectful in a classroom setting (Turner 2002). Stocks of knowledge also include transsituational roles, associated with gender, age, class, and ethnicity. One way of theorizing stocks of knowledge is to focus on the forms of cultural, social, and symbolic capital (Bourdieu 1986), or resources teachers have available to construct their teaching role. Cultural resources include teachers' knowledge of content, teaching methods, the students, and the culture of the school where they teach. Thus, a new teacher's stocks of knowledge might include an extensive knowledge of science, yet she may lack practical pedagogical knowledge of how to teach science with urban youth. Social resources accrue through relationships, networks, and bonds with others. Since a new teacher is just beginning to establish social networks, she may initially struggle to draw upon social resources effectively. Finally, symbolic resources stem from recognition of social values. New teachers have yet to establish reputations in the school and may initially have limited symbolic resources to draw on. Moreover, in urban science classrooms, prior notions about science and scientists may impede efforts to engage teachers and students from underrepresented groups in science teaching and learning roles. Yet, understanding resources as schema and practices (Sewell 1992) expands the notion of available stocks and knowledge to include the practices associated with a role, such as facilitating a discussion, managing group work, explaining concepts, and using available technology. 
Like many new teachers, Tina struggled and she admitted that she had no idea what she was doing, thus, her cultural, social, and symbolic resources for teaching in a high-poverty, urban school were inadequate. In taking on the role of teacher, Tina drew on preassembled roles, such as her memories of her own Fifth grade teacher; however, Tina found her resources, grounded in suburban, White, middle class schooling experiences, to be inadequate. For example, in her suburban schooling experiences students mainly did what teachers told them to do. The resistance she met from students initially baffled her. Tina also had not experienced balanced literacy as a student and had not adequately trained in the reading and writing workshop models her administrators demanded. She found it difficult to plan and implement literacy instruction. Tina described an adversarial relationship with the administrators. She felt that they only told her what was wrong with her teaching, not how she could improve. She blamed the administrators for 'leaving her high and dry' and failing to 'tell her how to do it right'.

Role forces include role-taking, role-making, and role verification (Turner 2002). Roletaking involves observing the gestures and actions of others to presume their standpoint and subsequent actions. Both teachers and students engage in role-taking as they determine each other's positionality and their likely actions. Role-making is what people do, the gestures they emit, and the actions they engage in, to establish their role and values in the situation and attain their goals. Finally, role verification involves reading the gestures and actions of others to determine whether they accept one's role-making, values, and goals in the situation. In the classroom, both teachers and students engage in efforts to role-make and verify their roles.

Facticity refers to a person's sense that the world is as they expect (Turner 2002). Becoming a teacher was a long-standing goal of Tina's and she expected to be able to take on the role of teacher, successfully. However, she was failing. The students did not verify Tina's efforts to role-make, evidenced by her struggles with behavioral and motivational issues. Thus, Tina's needs for facticity were not met and she experienced intense negative emotions (Turner 2002). For example, in the school, administrators paid a great deal of attention to how teachers handled moving their classes through the building. In public spaces, if students did not cooperate, the teacher had to admonish the students, stop the class until they became quiet, or make them go back to the classroom and start again. Tina felt great pressure to bring her class to the lab or other places in the building quickly and quietly. Her inability to do so was publicly humiliating. The administrators also failed to verify Tina's attempts to role-make or indicate what she was doing well. They also failed to make clear, at least from Tina's perspective, what she could improve.

Tina's struggles also provide a clear example of the privileging of aesthetic caring, or attention to school norms, over authentic caring. Tina's struggles suggested a need for added support and mentoring. As discussed earlier, during Tina's first year, five of the six teachers on her grade-level were new to the school. Two of the teachers, including Tina, were Teaching Fellows. The other Teaching Fellow quit by November. Teacher turnover places added demands on administrators and colleagues for mentoring and support. Whom do you turn to when most of the teachers on your grade level are new to teaching, or new to the school? Tina recalled poking her head out of the door of her classroom on the first day of school to confer with the other Fifth grade teachers and none of them knew how to bring their students down to lunch. Furthermore, the structures of school funding assign numbers of teachers based on numbers of students, rather than the neediness of students or teachers. Thus, Tina had a full class of 32 students, rather than a smaller class-size for her first year. She taught alone, rather than in coteaching, where she could work as an apprentice alongside a more experienced teacher. When schools add large numbers of new teachers 
each year, it overtaxes their capacity to mentor new faculty and implement reform-based initiatives. New teachers develop the perception that they must either sink or swim.

Finding support...

The eighth grade science teacher was one of the highly regarded teachers in the school. She had the ability to bring her class down to the Lab in silence. Her students arrived subdued, and I had to work a bit to bring their energy level up and their enthusiasm out. One day, I asked her, 'How do you get them to come down so quietly?' She said, 'I threaten them.' This teacher saw her role as akin to that of a warden.

At first, Tina struggled to understand the cultural norms for teaching in the school. It seemed like a guessing game and the administrators loved those people who figured it out, but they would not help the people who could not figure it out. Tina felt the administrators constantly dumped on her and that she was not doing anything right. She went home at the end of every day feeling that she had done 150 more things wrong that day than the day before. In school, Tina often resorted to tears. She entertained notions of quitting, feeling that she had no idea what she was doing, that she was useless; therefore, there was no reason for her to stay.

Her saving grace came from teachers on her grade level who banded together to cope with the common challenges of being new to the school. Tina especially relied on Randi. Although Randi was also new to the school, she had 6 years prior experience teaching Fifth grade in Arizona. Randi and other members of the Fifth grade team supported Tina, gave her suggestions, or just let her cry on their shoulders. They asked what they could do to help her. If she was having difficulty with particular students, she could send them to one of the other Fifth grade classrooms. The teachers ate lunch and planned units together. They were not just colleagues anymore. They were friends. They knew about each other's lives.

Little by little, Tina began to build a set of effective teaching practices. She observed Randi teaching and credited those observations with helping her see how to teach the 'right' way and get the management down. Tina noticed the special relationship Randi established with her students. Randi's students always wanted to be around her. They loved her. At the same time, Randi kept her students in line and maintained a good relationship with them. Randi was no warden. Tina began to understand what to do and tried to implement what she saw until she made it work. Tina realized that people could tell her what to do, but that for her, it was important to see it in action. She needed to see the pedagogical methods in place and how they worked to take on similar roles. One day, she was worried about how to do a lesson on food chains, so she asked Randi to model it for her, to teach her as she would teach her own students. Randi taught the lesson to Tina in the morning before school, and Tina taught the lesson easily. As she gained confidence in her teaching, she found that she was more willing to do hands-on activities in class. In Mathematics, she began using manipulatives, and in Science, she began doing experiments in the classroom.

Her favorite lab was the topographic maps. She loved it. The students loved it. Completing this lab in the classroom was a challenge. The colored water arrived on a cart in two big jugs. Students received plastic shoeboxes and a model volcano. Tina had to transfer the colored water to smaller bottles for students to fill the shoeboxes. After placing the lid on the shoebox, students overlayed a transparency and traced an outline of the volcano. Students added colored water in one-centimeter increments 
and after each addition, traced the outline of the volcano. The result was a topographic map of the model volcano. At the end of the lesson, students emptied the shoeboxes back into the jugs. Tina saw how her students loved working with the water and the wax pencils, and she loved the students', 'Oh! I get it!', moments when they realized that a topographic map was a bird's eye view. By the end of her first year, Tina was able to teach! She said, 'Everybody always says if you don't get it in the beginning of the year, that's it. You're totally done. And I didn't get it in the beginning of the year last year. It was quite obvious that I didn't get it in the beginning of the year.' The fact that she was able to 'get it' by the end of the year gave Tina the confidence to believe the following year her classroom management and teaching had to be better. She went into the summer knowing the next year would be a better year, because she knew so much more.

Roles are shaped by four attributes: (a) expectations about how people should behave in particular social situations; (b) the actual behaviors of individuals in particular roles; (c) resources used to obtain desired outcomes or positions in social structures; and (d) symbols that signify who people are, what they will do, and how they should be treated (Turner 2002). For example, the role of teacher includes: (a) cultural, social, and historical expectations about how teachers should act; (b) how they teach; (c) how teaching enables teachers to obtain resources, such as student performance or recognition; and (d) how teaching takes on symbolic meaning within the school community. In Tina's school, good teachers controlled their students. Classes that were calm and engaged in seatwork were more highly regarded than classes that were noisy or chaotic, regardless of the critical thinking or learning that might be happening. These school norms were directly at odds with adolescent development and the need for adolescents to have more control over their decisions and goals and to engage in social interaction. Thus, the teachers had to negotiate competing aestheticlauthentic sets of expectations from the school, their own understanding of teaching, and students' expectations about how they should act in the classroom. At the same time, resources to support new teachers in the school were inadequate. Nevertheless, the teachers' ability to establish a more authentic caring community, at least on their grade-level, served to mitigate some of the ways the larger school community left Tina and the other new teachers to 'sink or swim'. The teachers' common experience of 'being in the same boat' and their efforts to support one another fostered a sense of solidarity. They developed close friendships. These social resources helped fill the gap and expand Tina's pedagogical resources for enacting the role of effective urban teacher.

The mechanism by which cultural, social, and symbolic resources influence role-making is through the processes of role-taking and role verification, how others perceive and verify a person's attempts to role-make. Specifically, role forces largely influence encounters through the tendency of individuals to 'seek to discover the underlying role that others are playing' (Turner 2002). Role verification is high-stakes. If a role, like that of teacher, is highly salient to an individual's identity, then they will experience strong, positive emotions when the role is verified. However, if the role is not verified, then they will experience intense, negative emotions. Furthermore, when individuals attribute their failure to role-take to themselves, negative emotions will be directed at themselves, and if they attribute their failure to others, such as school administrators, their negative emotions will be directed towards those others. Much of the generative process of role-taking, rolemaking, and role verification occurs at the subconscious level as individuals continually assemble and reassemble roles during face-to-face encounters. The maxim 'actions speak 
louder than words' exemplifies the hidden or unconscious ways in which role forces interact during face-to-face encounters.

Tina's physical stance and positioning in the classroom with respect to the students, her tone of voice, eye contact, facial expressions, and hand movements all conveyed meaning to students as they attempted to interpret Tina's gestures during role-making. To the extent that Tina was successful, students would verify her role as teacher by engaging in the role of student. Emotions serve as the main indicators of these mostly unconscious processes, and the valence, or strength of the emotions directly indicates how salient a given role is to a person's core self-understanding, or identity. Tina experienced intense negative emotions and bouts of crying during the early months of school, and seriously considered quitting. By observing Randi, Tina was able to model her pedagogy around a more authentic caring set of practices. Instead of threatening students, she could convey her care and concern for students and maintain a safer, learning environment. The high point occurred when she was able to complete the topographic mapping activity in the classroom. Tina's strong positive emotions in talking about the significance of this lab affirm the high salience of effective teaching to her identity. Importantly, she defined effective teaching in terms of her ability to manage the materials and student behavior during the activity, and from her students' engagement and their ability to conceptualize an abstract science concept.

\section{Expanding her resources to teach science}

During the 2 years of our collaboration, Tina had many opportunities to coteach science. For example, in May 2003 we cotaught a unit on invertebrates. Our goal for the unit was to study representative animals from each invertebrate group. For mollusks, we would be observing snails collected from my garden. At our weekly science lunch, the teachers observed the snails, established a list of process skills and concepts students should develop through observation of the snails, and reviewed several activities from teacher resource guides in the Lab. To incorporate measuring skills, the teachers decided that students should measure the height, length, and mass of their snail. Each group of students would record their data on a class chart, and students would write summary statements about the class data, comparing and contrasting their small-group results with average data for the class. Students would also record observations of the snail's color and shell pattern, label a diagram of a snail, and observe its behavior. As the teachers began scheduling the times and dates for the snail lab, it became clear that due to scheduling conflicts, Tina and I would need to teach the first snail lab in Tina's classroom, not in the Lab. Despite the teachers' view of me as 'expert', the snail lab was a new lesson for me, and I was not sure how students would respond to the lesson or how long the activities might take. In the Lab, I knew how to group students, how to set up materials for their use, and where to find resources if a lesson needed adjustment. Using Tina's classroom for the first time I would be teaching this lab was more of a challenge. The students' slanted desks made it difficult to position trays and triple-beam balances and irregular group sizes made sharing materials more difficult. In addition, given Tina's struggles with classroom management, I believed her class might be harder to manage in their classroom, than in the Lab.

On the day of the lab, I loaded up a cart with the materials and headed upstairs. Tina and I quickly set up the room and then she went to bring the students up from lunch. After a quick introduction explaining the goals of the lesson, how to care for the snails, and that the snails would be released back into my garden, the students began 
working. Despite my visions of chaos and confusion, the lesson went smoothly from beginning to end. The students were excited about the snails and virtually all students overcame their apprehensions about touching them. They quickly figured out how to balance the triple beam balances across two desks to take measurements of the snail's mass. Tina and I circulated and helped the students as they worked in their small groups. We noted how gently the students were handling the snails and how proficiently they used the balances. We also noted that many students needed instruction in how to begin a measurement of length at the zero point on a ruler and incorporated a mini-lesson on ruler measurement. By the end of the two periods allotted for the snail lesson, the class completed a data chart and Tina reviewed it with the class. Throughout the lesson, Tina effectively reinforced where students should be and what they should be doing. She facilitated the closing discussion and students demonstrated their ability to use the class data chart to compare results between each group. The cleanup proceeded smoothly and upon leaving, I told Tina, 'You've really come a long way this year. It's so good to see'.

As a staff developer, I modeled an inquiry-based science lesson incorporating the use of live animals. As a researcher, I was interested in how students and teachers responded to efforts to expand students' opportunities to learn science. How did students feel about their expanded opportunities to learn? Could teachers articulate what was different about our approach or why it mattered for their students or their teaching practices? From a social justice perspective, I wanted to know what impacts collaborative science teaching and learning had on teachers' commitments to sustain more equitable science teaching and learning in their classrooms. However, Tina taught me another lesson. For a self-contained classroom teacher, science teaching, regardless of how much we compartmentalized it in our thinking and planning, could not be divorced from the teacher's developmental trajectory or the cultural and political contexts of her classroom or school. Tina's ability to take on the role of a more effective, caring teacher facilitated her ability to teach science. Her students' abilities to take on communal roles enabled them to share resources, assign tasks, and communicate effectively.

By coteaching, Tina was actively able to assemble stocks of knowledge about science teaching, including preassembled roles, generalized roles, and transsituational roles. During the snail lab, once the students set up their materials and began measuring their snail's mass, height, and length, Tina noted that I was encouraging more than one student to make each measurement. I wanted to provide more students with practice using the triple-beam balance and ruler and increase the reliability of the group's measurements. I then observed Tina providing similar directions as she circulated to other groups. When we noticed several groups were having difficulty with measuring from the zero point on the ruler, we conferred on the side and decided to stop the activity for a mini-lesson on measuring from the zero point on the ruler. Tina presented this mini-lesson, drawing on and connecting to a previous math lesson she had given on measurement. Finally, Tina took the lead to explain the homework, which required students to make comparison statements between their snail and the average class data we had compiled, giving examples from the data on the chart. To give the students instructions, Tina assembled prior knowledge of reading data charts, comparing and contrasting data, her understanding of what students might have difficulty with, and her understanding of the goals of the lesson. By observing and coteaching science lessons, Tina extended her understanding of science teaching as an embodied practice, including posture, facial expressions, tone, movement through the classroom, management of science materials, and organization of 
student activity. She increased her knowledge of science, and constructivist approaches to teaching science, including modes of questioning students. Furthermore, Tina demonstrated fluidity, or an ability to assemble effective roles in response to the learning and/or management needs in the classroom. As a result, Tina's students verified her role as teacher.

Authentic caring pedagogy is responsive to individual and collective student needs. Tina's turning point came when she shut her door and began to focus on gaining the trust and respect of her students and being fair, practices she saw Randi model. Thus, learning strategies for developing caring relationships with her students was crucial for Tina's survival as a first-year teacher. Yet, these fundamental strategies were not emphasized during her training period for the Teaching Fellows program, in her graduate education courses, or in the literacy framework training and professional development provided by the school. Instead, a focus on curriculum standards, pedagogical content knowledge, and pressures for command and control prioritized aesthetic caring concerns. Our attention to both authentic and aesthetic caring provided more optimal results in terms of teacher development, teacher efficacy, student engagement, and student learning.

\section{I don't speak Spanish, they don't speak English}

In her second year, Tina taught a class with predominantly English language learners (ELLs). About half of the class consisted of newcomers with very little English language ability and Tina struggled to communicate with and get to know her students. Tina explained, 'It's so hard for them ... to communicate with me since I don't speak Spanish and it's hard for me to communicate with them because they don't speak very much English'. Tina's placement with ELL students is a clear example of the ways in which the neediest students often receive the least experienced and least qualified teachers. Tina's assignment also reflects a growing trend towards denying ELLs bilingual or dual language programs in an effort to get students to learn English more rapidly by immersion.

To communicate with her students, Tina placed the students in teams where at least one group member had enough English and Spanish skills to translate. Tina explained, 'So if they're working in a team and they can talk to their team in Spanish and their teammates can talk to me in English ... it makes it that much easier'. Nevertheless, Tina knew that it was going to be difficult to get to know her students, especially since the class had been with the same teacher for third and fourth grade. She believed that she did not have an automatic 'in' with the students because she did not share their language or their culture, so she focused on connecting with them on a personal level. Tina said, 'I think a lot of it was just spending time one-on-one even if it was just over a book talk...really getting to know their feelings. Whose mom's having a baby? When did they come to the United States? What country did they come from?' Tina made time in little spurts throughout the day and throughout the year, in order to get to know the students in her class. Although Tina made time to get to know her students, she still had little understanding of multiculturalism. To Tina, multiculturalism was having 'Hispanic kids' and 'African-American kids' in her class. Their cultures were multicultural for her, and her 'White' culture was multicultural for them. She recognized that she was from a different culture and believed that multiculturalism would not be teaching about African-American or Hispanic cultures. Instead, multiculturalism would be teaching about cultures her students did not already know about. 
By her second year, Tina was willing to let her students struggle to understand science concepts over the course of several lessons, rather than immediately explaining a concept when her students did not understand. She told me, 'Sometimes I feel like I can go a little further to see if they get it because the concept is bigger than one lesson and if you keep going it might make more sense to them...'

She gave the example of how her students were screaming and going crazy when they inflated a balloon by combining vinegar and baking soda in a bottle. This activity became the basis for students' understandings of the properties of matter and chemical reactions. Tina was comfortable allowing the students to scream and go crazy and did not feel she needed to launch directly into explanations of what was happening; rather, explanations could come later in the unit. Thus, for Tina, science 'worked' when her students were 'going crazy' because she believed she could harness that excitement and positive emotional energy towards other learning goals.

The challenge of educating ELL students continues to grow, while efforts to deny immigrant youth access to bilingual programs have mounted (Gándara and Contreras 2009). In her study of Mexican immigrant youth, Valenzuela (1999) documented how schooling becomes a 'subtractive process' that divests students 'of important social and cultural resources, leaving them progressively vulnerable to academic failure' (p. 3). Immigrant students lost their language, culture, and their sense of 'educación', or education that includes caring and respectful relationships between students and teachers. Tina knew that she needed to connect to her students if she hoped to have a better year than her first year. She made it a priority to establish relationships with her students across differences in language and culture. She made time for authentic caring and opportunities to learn. Yet, Tina could not articulate how to build on students' cultures in ways that might enhance the relevance of their learning or foster the development of students' cultural competence (Ladson-Billings 1994). Her statements affirm findings, that 'neither the school setting, nor the Fellows program, nor the college coursework has made a sufficient attempt to ... bridge the gap of cultural understandings with their poor urban students' (Costigan 2005, p. 132).

Asserting her autonomy...

In May 2004, I entered the elevator at the school and saw Randi and Tina. Tina told me she did the owl pellets. The week before, Randi led an after school professional development session on owl pellets and gave the team a two-week unit plan on owls and food webs. The owl pellet dissection was supposed to be one of the culminating activities in the unit. Tina had not even started the unit, but she had done the owl pellet activity. Furthermore, I knew that half her students were out on a field trip. I asked Tina, 'What about the rest of the students?' She answered nonchalantly, 'Oh. I'm going to do them again with the whole class, but this way the ones that were there will be able to help the ones that weren't.'

Later, Randi informed me that two other teachers on the grade just 'did' the owl pellets. I was particularly frustrated because I believed we had worked so hard during the second year of our collaboration to focus on more than just 'doing' science. During the first year, our primary focus had been providing students with more opportunities to learn science. By teaching Earth and Physical Science units that had not been taught the year before, we significantly expanded the amount of 
science students were taught. This year, we were trying to emphasize student learning by establishing clear learning goals, incorporating performance assessments, and tailoring activities to students' needs. It seemed to me that Tina and the other Fifth grade teachers, who had done the owl pellets without the other instructional components, were trivializing the importance of quality in our work with students. The teachers were supposed to embed the owl pellet dissection in a unit that helped students understand the structures and functions of owls and other vertebrates and the interrelationships among organisms. They had agreed to launch the unit with a read-aloud from 'Poppy', by Avi, as Randi had done the year before.

I left the encounter angry because I believed Tina did not verify my role as science staff developer and that my goals for equitable science teaching in the school had been undermined. Tina left the encounter on the defensive, because we had failed to verify her role as a teacher who could make decisions about her science curriculum that differed from the views of her colleagues. Although Tina claimed she would complete the rest of the unit with the students, and that she would be repeating the owl pellet activity, at the time, I could not see the value of her approach to this unit. Rather, I was concerned that Tina had used the owl pellet activity as a fill-in for the last two periods on a Friday when half her class was on a field trip.

This story clearly illustrates the compromises teachers might make in navigating competing aestheticlauthentic caring goals. Aesthetic goals to maintain command and control of her class could have led Tina to assign seatwork or move on with her planned curriculum. Instead, Tina chose to fill the time with a novel investigative activity that her remaining students could enjoy. At the same time, Tina risked the displeasure of Randi and me. Randi developed the unit plan, I assembled the materials, and together, we attempted to prepare Tina to teach the unit, 'the right way'. Tina risked the chance that we would not verify the role she was making. As stated earlier, role verification is high-stakes for all participants because of the level of emotions, positive or negative, that can be aroused by meeting, or not meeting, participants' transactional needs during an encounter (Turner 2002). Tina took a good deal of criticism from some of her colleagues for deviating from the unit plan. Some of their critiques were justified as Tina privileged self-interest-what can I do to fill the time?-over collegiality-How should I implement the unit that Randi planned? However, Tina had not taught this lesson before so she may have felt more comfortable with a smaller group for her first owl pellet dissection. Having half her class out on a field trip was a contextual constraint that Tina could have dealt with by giving the students who remained busy work. Instead, Tina chose to engage the remaining students in an investigative activity, showing care for her students and their learning time. In this way, Tina began to take more ownership of her teaching, even at the risk of her colleagues' displeasure. Thus, Tina navigated the aestheticlauthentic caring dialectic by negotiating and compromising between competing goals of collegiality, self-interest, student interests, and contextual constraints.

Fulfilling her promise...

Tina did do the owl pellets twice, just as she claimed she would. She gave students the lab sheets, went over the procedure, and what they needed to do, step-by-step. She passed out the owl pellets, then said, 'Go for it. See what you find.' She chose not to give students the bone sorting charts until after they had started because she 
did not want them to know they were going to find bones. At first, the students would not touch the pellets, but after a few minutes, they all began working on the pellets. Once they began finding bones, she gave them the bone sorting charts. After the students organized the bones into skeletons, and glued them, she had the students come together and talk about what they found. 'What was it? Why was it there' The students loved the activity, and they had so many questions that Tina decided to extend the unit. They read nonfiction about owls, and made board games using the facts they had learned about owls. Tina believed that once she got the 'hook', where students saw that owl pellets were fun and they wanted to know more about owls, she could draw on students' interest and engagement to incorporate literacy activities. She said, 'When they're really into something, it's easy to pull everything else in. So now I'll do "How To" in their writing because they have to do a direction booklet and grammar for the questions.' Tina reiterated, 'So if I find that they're really into something; I'll extend it because I could get in other things that I have to do.'

Randi and I had a more structured approach to teaching. We believed that in order for teaching to be equitable-an experience wherein everyone learns-students required some background or context for their work, such as a 'wonder chart', asking students what they wonder about owls. On the other hand, Tina approached teaching in general, and science in particular, in a different way. For Tina, it was important that her students 'investigate' and figure things out by themselves. Furthermore, Tina believed that when students have the opportunity to figure things out for themselves they feel better about their learning. Tina did not want her students to learn by just listening; instead, she wanted her students to feel good about their learning and develop a sense of efficacy in science. Thus, for Tina, science learning experiences needed to place students in the role of investigators because when students were able to figure it out by themselves, they would experience positive emotions and feel more successful. Tina's students also would be able to attribute their success in the role of investigator to their efforts, increasing their sense of accomplishment.

Tina's implementation of the unit was consistent with her approach to teaching science and paralleled the approach we took during the snail lesson a year earlier. Tina wanted her students to, 'come up with it'. She wanted them to figure things out for themselves. Tina positioned herself as a facilitator, rather than a controller of student learning. Students engaged in critical thinking and actively produced and used knowledge about the owl pellets. Tina used the opportunity of the field trip to solidify her relationships with the remaining students through their mutual enjoyment of the owl pellet dissection. By positioning the students as explainers and helpers when the rest of the class studied the owl pellets, Tina affirmed and enabled the students to use the science knowledge they had gained. Tina's adjustments to and extensions of the unit plan demonstrate her awareness of the needs of her students as well as a willingness to capitalize on her students' interests. Although I do not believe Tina planned or predicted such a favorable outcome to the unit, in the end, her students developed a core of knowledge and practiced an array of literacy skills. Randi criticized Tina for deviating from the unit plan because she believed Tina had not provided the students the proper basis for learning from the owl pellets. Had Tina simply done the owl pellets a second time without the other unit activities this charge might have been true. Instead, by extending the unit when her students were 'hooked', Tina used science instruction to affirm authentic caring relationships in the classroom, develop students' literacy skills, and provide her students with rich opportunities to learn science and language. Tina was no longer just doing what we told her to do. 


\title{
Illuminating role forces and their impacts on teacher development
}

\author{
Re-Visiting Renee
}

At the beginning of this paper, I told the story of Renee, a first-year teacher in a New York City public school, struggling to gain control of her class. In spring 2002, I began working with Renee and Nathan, a student teacher, to develop a unit of instruction on animals. The unit included observations of goldfish, the set-up and maintenance of freshwater aquaria in the classrooms, and culminated in a perch dissection. I was working with Nathan on planning lessons, preparing student handouts and lab materials, integrating technology, delivering effective lessons, and assessing and evaluating student work. At the same time, I was working with the Renee to push and extend her notions of what was possible with urban middle school students in science, even at the fifth grade level. This was my consistent political focus. I was tired of hearing what urban middle school students could not do because of their behavior, skills, prior preparation, or motivation. I had worked in a gifted school before. I had worked with small class sizes and when I began working in New York City public schools; I found no difference. My students could learn. As a Latina, I felt that these were my kids, my people. I wanted to show, not tell what my students of color...my students in poverty...my bright, curious, engaging, thoughtful, challenging students could do. I wanted to share science with the students in part for sheer enjoyment and appreciation, but mostly to refute the ways in which science has played the role of gatekeeper in our society and excluded many children like them.

Through many conversations with her, I know that Renee wanted to make a difference with New York City public school youth. I felt sad when she left after her first year to teach closer to home. Renee had the makings of a great teacher, and with the right support, she would have become successful. I like to think that she has become that successful teacher. Yet, in thinking about Renee, I notice the difference between her first-year experiences, and Tina's. Tina stated that without the support of her colleagues, she would have felt useless and would have quit. I do not doubt Tina's sincerity when she said this. Renee did not have the support of colleagues like Randi. During her first year, Renee did not have other teachers to call on when she stayed late after school. Renee was not part of a supportive community where despite all the real difficulties of teaching in New York City schools, and through all the tears, there was also joy. I am sure she was lonely, at times, in her quest to become an effective teacher in any subject, let alone science. I do not know if Renee's beliefs or attitudes towards science or her students changed because of our collaboration. Nevertheless, it was the seed for this larger study and marked a crucial change in the way I worked with teachers. I realized that curriculum development and implementation support could be a way to transform science teaching and learning in urban classrooms in ways that professional development workshops and telling teachers how to teach science had not. Thus began this journey towards uncovering a need for authentic caring in transforming urban science education and promoting social justice-a journey throughout which my consistent role was to keep science on the map of what teachers and students were doing.

Attention to role forces highlights the ways institutional practices of schools frame the spaces of possibility for new teachers, and by extension, the students in their classrooms. 
Initially, Tina's cultural, social, and symbolic resources for the role of urban teacher were inadequate to position her to role-make and she was clearly failing. Neither the students nor the administration verified her role. Tina received negative sanctions from the administrators, who told her what was wrong with her teaching, rather than how she could improve. Disconnects between Tina, a White, suburban, novice teacher, and her Black and Latino/a students, across race, culture, ethnicity, language, and class also detracted from Tina's ability to role-make. Teaching and learning in Tina's class suffered, and her failure to role-make and receive verification for her efforts were a source of deep negative emotions about herself, the school, and the administrators. A 'sink or swim' approach to new teacher induction is another form of educational triage, or subtractive schooling. Students in those teacher's classrooms are also likely to fail.

At the same time, students bring strong pressures to bear as they verify, or do not verify, the roles new teachers try to make. Teachers were under intense pressures in the school to display command and control of their classes in the public spaces of the school, such as hallways and stairwells. Administrators often made unannounced visits to classrooms and valued quiet and order in the classroom. Initially, Tina's inclinations were to avoid mess and chaos in the classroom and she avoided using manipulatives or hands-on activities. However, caring relationships between Tina and her colleagues enabled her to expand her cultural, social, and symbolic resources for teaching in an urban school context and become more successful. School structures, including grouping Fifth grade classes into a common wing and providing common lunch periods and planning time facilitated close relationships among teachers on the same grade-level. Tina's social networks expanded to include the Science Lab and through coteaching, Tina was able to gain fluidity, or an ability to assemble effective science teaching roles in response to the learning or management needs in the classroom.

As Tina's confidence in her management grew and her cultural, social, and symbolic resources for teaching expanded, she began to prioritize a more investigative approach to teaching science. Tina and her students received positive exchange payoffs, as students responded positively to science activities, such as topographic mapping and owl pellets, and verified the role Tina was trying to make. Tina's science pedagogy contributed to more authentic caring relationships, and authentic caring relationships enabled Tina to take teaching risks and do investigative activities in the classroom. Tina's ability to assert autonomy in the owl pellet unit and offer a strong rationale attest to her development from a teacher who 'had no clue' to a teacher who could make and enact decisions about her science teaching. Without intervention, Tina might have left the profession. Instead, Tina's ability to 'get it' enabled her to feel confident about returning for a second year, and by her third year, Tina became a science specialist in the school, teaching only science.

Tina's progress mirrors patterns found in a larger scale study of 38 Teaching Fellows (Costigan 2004). The Fellows began with noble goals of making a difference in the lives of disadvantaged youth and admitted fears of failure. Then their idealism met the realities of urban classrooms, including unruly students, and a mismatch between the pedagogical methods they were learning in their courses, and the actual work they needed to do to create a safe learning environment. They began to measure their success based on their ability to engage and manage the two or three most disruptive students in their classes. Most saw themselves as increasing in competence by the end of the first year. Like Tina, many Fellows seemed to need more hands-on opportunities to see educational theories in practice in order to be able to take up those practices. Thus, "coursework only became meaningful when it was grafted on to their developing personal narratives as informed by hands-on daily practice' (Costigan 2004, p. 138). 


\section{Aesthetic|authentic caring in urban contexts}

The aestheticlauthentic caring dialectic broadens the scope of caring beyond the nature and extent of interpersonal relationships to the theories and actions that ground a struggle for better schools. The dialectic focuses on the conditions for caring, including a critical awareness and transformation of structural and institutional sources of inequality in schools (Hooks 2003). Thus, the focus shifts from caring for - to caring with-the process of engaging with others in the struggle-and caring in - the role of the social context in framing the decisions and values that undergird the roles teachers attempt to make. Examining role forces and describing the cultural, social, and symbolic resources available to new teachers as they begin their profession is particularly crucial in understanding new teacher development. We can begin to explore how teachers use and expand upon cultural, social, and symbolic resources for teaching along their developmental trajectory.

Authentic caring explicitly refers to Tina's ability to enact an ethic of caring that encompassed her relationships with other teachers, with her students, and with the science curriculum and pedagogy in her classroom. School policies and procedures that place caring central to the mission of schooling may ensure a basis for building classroom communities that foster respect, solidarity, and learning. Such a school culture would not allow a new teacher and her students to 'sink or swim' or leave new teacher mentoring to chance. Teachers' sense of efficacy—or knowing that they are teaching effectively and that their work makes a difference - attracts and keeps them in the profession (Nieto 2003). Thus, teachers' ability to role-make and verification of their role-making efforts are crucial to their sense of efficacy and their retention in the profession. Clearly, 'sink or swim' approaches to teacher induction, particularly in high-poverty, low-income schools, guarantee that an unconscionably large number of teachers and students will fail. Yet, how do we ensure that new teachers are prepared successfully to take on their roles?

New teachers require adequate apprenticeship periods in the communities where they hope to work. Apprenticeship opportunities should include ways of understanding cultural, linguistic, and social differences as resources to be capitalized on in teaching and a clear articulation of expectations about the role of a teacher. Assessment and enhancement of prospective teachers' cultural, social, and symbolic resources-spanning content, pedagogy, and the cultures of the students and community they will serve, may improve novice teachers' attempts to role-make. New teachers should also have opportunities to assemble effective roles in scaffolded situations, such as observing model lessons and coteaching. Finally, modes of mentoring, assessing, and evaluating new teachers should attend to the emotional dimensions of becoming a teacher. Understanding the emotional toll a lack of role verification brings may serve to increase efforts for adequate mentoring and targeted preparation, particularly for teachers who choose alternative certification routes.

Promoting changes in teachers' practices requires an appreciation for the complex relational and contextual interactions in which teaching occurs, to move teachers and students from a position of caring about, to caring in action, within their particular context. When 'people feel they have a voice in matters that affect them, they will have greater commitment to the overall enterprise and will take greater responsibility for what happens ... the absence of such a process ensures that no one feels responsible' (Sarason 1990, p. 61). Science curriculum development engaged Tina in determining what students should know and be able to do, how students should develop their knowledge and skills, and by what performances she would evaluate her students. Tina's stories point to some of the ways in which science education reform and classroom-level collaboration might position 
science curriculum development and implementation as a lever to affirm authentic caring relationships and improve teaching and learning across the curriculum.

Navigating the aestheticlauthentic caring dialectic was both a struggle toward open spaces of possibility for authentic caring and resistance to the primacy of aesthetic caring forces in the school. Aesthetic caring forces, such as inadequate mentoring for new teachers, prioritizing high-stakes exams, and a lack of science materials divested teachers and students of resources and capacities that could be used to enact a more socially just science curriculum. Science education has become increasingly marginalized in highpoverty, low-performing schools, by a narrow focus on the basics-reading, writing, and mathematics - and teaching to high-stakes tests, rather than teaching for understanding across all curriculum areas. Preparing teachers for the role of navigating competing aestheticlauthentic demands, let alone their own needs for role-verification, present increasing challenges for teacher education.

Caring for and caring withlin required acts of resistance on the part of the teachers. Tina continually negotiated, debated, and enacted resistance as she made sense of the school culture, the expectations of administrators for her teaching, her goals and interests, and the needs and interests of her students. Resisting subtractive forces reified Tina's beliefs that she could make a difference, individually and collaboratively, in the lives of urban middle school youth. Tina resisted the notion that students in her high-poverty, low-performing school should only learn the basics. Collaboration with colleagues and with the Lab and engaging in science curriculum development emerged as integral resistance and authentic caring strategies that promoted more effective classroom management and risk-taking and enhanced Tina's sense of efficacy and science teaching. Through collaboration and resistance, learning about science teaching became a process that enhanced Tina's cultural, social, and symbolic resources.

Acknowledgements The author would like to thank the following reviewers: Kenneth Tobin, Wolff Michael Roth, Gale Seiler, David Geelan, Edna Tan, and Konstantinos Alexakos for helping me tell this story. I would also like to thank my dissertation advisor, Angela Calabrese Barton, without whom this story might not have been told. Finally, I thank Tina for allowing me to be a part of her narrative of becoming an urban science teacher and to share her story with you.

Open Access This article is distributed under the terms of the Creative Commons Attribution Noncommercial License which permits any noncommercial use, distribution, and reproduction in any medium, provided the original author(s) and source are credited.

\section{References}

Bourdieu, P. (1986). The forms of capital. In J. G. Richardson (Ed.), Handbook of theory and research for the sociology of education (pp. 241-258). New York: Greenwood.

Calabrese Barton, A. (2001). Critical ethnography: Science education in urban settings—seeking new ways of praxis through critical ethnography. Journal of Research in Science Teaching, 38, 918-939.

Clandinin, D. J., \& Connelly, F. M. (2000). Narrative inquiry: Experience and story in qualitative research. San Francisco, CA: Jossey-Bass.

Clandinin, D. J., Pushor, D., \& Orr, A. M. (2007). Navigating sites for narrative inquiry. Journal of Teacher Education, 58, 21-35.

Costigan, A. (2004). Finding a name for what they want: A study of New York City teaching fellows. Teaching and Teacher Education, 20, 129-143.

Costigan, A. (2005). Choosing to stay, choosing to leave: New York City teaching fellows after two years. Teacher Education Quarterly, 32, 125-142.

Freire, P. (1970, 1998). Pedagogy of the oppressed. New York: Continuum. 
Geelan, D. (1997). Weaving narrative nets to capture school science classrooms. Research in Science Education, 27, 553-563.

Gilbert, A., \& Yerrick, R. (2001). Same school, separate worlds: A sociocultural study of identity, resistance, and negotiation in a rural, lower track science classroom. Journal of Research in Science Teaching, 38, 574-598.

Hooks, B. (2003). Teaching community: A pedagogy of hope. New York: Routledge.

Knight, M. G. (2000). Ethics in qualitative research: Multicultural feminist activist research. Theory into practice, $39,170-176$.

Ladson-Billings, G. (1994). Dreamkeepers: Successful teachers of African-American children. San Francisco: Jossey Bass.

National Commission on Teaching \& America's Future (NCTAF). (1996). What matters most: Teaching for America's future. New York: National Commission on Teaching \& America's Future.

New York City Department of Education. (2008). NYC Teaching Fellows: About us. Retrieved April, 23, 2009, from http://www.nycteachingfellows.org/mypersonalinfo/downloads/NYCTFPressKitNovember 2008.pdf.

Nieto, S. (2003). What keeps teachers going? New York: Teachers College Press.

Noddings, N. (1995a). A morally defensible mission for schools in the 21st century. Phi Delta Kappan, 76, 365-368.

Noddings, N. (1995b). Teaching themes of care. Phi Delta Kappan, 76, 675-676.

Pole, C., \& Morrison, M. (2003). Ethnography for education. Berkshire, England: Open University Press.

Roth, W. M., Hwang, S., Lee, Y.-J., \& Goulart, M. (2005). Participation, learning, and identity: Dialectical perspectives. Berlin: Lehmanns Media.

Sarason, S. B. (1990). The predictable failure of educational reform: Can we change course before it's too late? San Francisco, CA: Jossey-Bass.

Settlage, J., \& Meadows, L. (2002). Standards-based reform and its unintended consequences: Implications for science education within America's urban schools. Journal of Research in Science Teaching, 39, $114-127$.

Sewell, W. H. (1992). A theory of structure: Duality, agency, and transformation. The American Journal of Sociology, 98, 1-29.

Strauss, A., \& Corbin, J. (1998). Basics of qualitative research: Techniques and procedures for developing grounded theory. Thousand Oaks, CA: Sage.

Turner, J. H. (2002). Face to face: Toward a sociological theory of interpersonal behavior. Stanford, CA: Stanford University Press.

Valenzuela, A. (1999). Subtractive schooling: U. S.-Mexican youth and the politics of caring. Albany: State University of New York Press.

\section{Author Biography}

Maria S. Rivera Maulucci is an Assistant Professor of Education at Barnard College. She teaches courses in secondary pedagogical methods and science education, including "Science in the City," a seminar that brings together in-service teachers from a New York City public school, pre-service teachers from the Barnard Education Program, and science majors to develop their science pedagogical and content knowledge and foster student achievement in science. Her research interests include multicultural and critical science pedagogy and social justice teacher education. She received her Ph.D. in Science Education from Teachers College, Columbia University, Master of Forest Science from Yale, and B.A. in Biology from Barnard College. Maria has taught middle level science, mathematics, and technology at De La Salle Academy in New York City and worked as a school science and mathematics staff developer and a district science staff developer in New York City public schools in the Bronx. 